\title{
Women's health care in low income countries
}

\author{
Patricia J. Numann
}

Received: 25 December 2013 / Accepted: 28 December 2013 /Published online: 12 February 2014

(C) The International Urogynecological Association 2014

\section{J. Marion Sims Lecture}

American Urogynecologic Society, 34th Annual Scientific Meeting, Las Vegas, 17 October 2013

J. Marion Sims was committed to the resolution of some of the most challenging problems of women. He developed techniques for fistula repair and built programs and facilities to care for women. If alive today I am certain he would be at the forefront of the topic I wish to discuss.

The surgical care of people in low income countries has become a passionate concern of mine. Being the first woman surgeon in my community, I was frequently asked to care for women and address concerns women had about their care. Covering the emergency department, I saw the toll domestic violence had on women. I learned the benefit of supporting our women's shelter and other charities that empowered women. When I became President of the American College of Surgeons (ACS) in 2011, I visited surgical programs in many countries and met with surgical leaders about their problems. I found out that surgical care was not part of the World Health Organization's (WHO) public health mission. I found out only $4 \%$ of the WHO budget was allocated to surgical problems; yet, $11 \%$ of deaths worldwide were from surgical disease, two thirds of which could have been prevented. More people die annually from surgical problems than acquired immunodeficiency syndrome (AIDS), tuberculosis (TB), and malaria combined. The majority of deaths were in the young in low income countries. Many were in young women related to complications of pregnancy and childbirth [1].

The acknowledgment by the WHO of the importance of surgical disease is critical to raising funds and developing programs to address these surgical issues. The World Bank

P. J. Numann $(\bowtie)$

American College of Surgeons, 633 B. Saint Clair St., Chicago,

IL 60611-3211, USA

e-mail: numannp@upstate.edu gives priority to programs endorsed by the $\mathrm{WHO}$ as mission critical. The Millennium Development Goals of the WHO and World Bank for 2000 were:

- Eradicate extreme poverty and hunger

- Achieve universal primary education

- Promote gender equality and empower women

- Reduce child mortality

- Improve maternal health

- Combat human immunodeficiency virus (HIV)/AIDS, malaria, and other diseases

- Ensure environmental sustainability

- Develop a Global Partnership for Development

and have been effective at reducing these problems [2]. The development goals for 2015 are currently being formulated. For several years groups have been trying to have a resolution introduced at the World Health Assembly (WHA) to include surgical care in the WHO Mission. This has to date been unsuccessful. This year there is a real possibility that the resolution can be amended to a resolution on universal health care which is already on the agenda. Surgical groups must speak up and be heard through their delegate to the WHA. The WHO does currently fund the Global Initiative for Emergency and Essential Surgical Care which has improved the situation in the 34 countries involved in the program. The WHO Safe Surgery Saves Lives Surgery Checklist has also been a very positive program to reduce operative mortality. So much more needs to be and can be done.

The Copenhagen Conference in 2008 (www. copenhagenconsensus.com) stated that provision of surgical care was one of the 25 most cost-effective investments for low income countries. Dr. Jim Yong Kim, President of the World Bank (www.worldbank.org), has stated his goal is to eliminate extreme poverty by 2030 and eliminate poverty worldwide by 2050, support smart business models, reduce inequality, and 
focus on the lowest $40 \%$. Providing surgical care will increase the workforce and improve the economic status of low income countries.

Low income countries as defined by the World Bank have an annual income of US $\$ 1,035$. The poverty level income is less than US\$1.25 per day; 827.8 million people live in these countries. The majority of the population lives on coastal disaster-prone land. The average life expectancy is 58 with a range from 50 to $60 ; 99 \%$ of the world's maternal deaths, deaths from trauma, and cervical cancer occur in low income countries. It is estimated that 1-2 million children await surgery for congenital heart disease in these countries.

Women in these countries are less likely to be educated and have fewer economic resources than men. Women are disproportionately affected by TB and HIV. Cultural traditions continue to support genital mutilation and sexual violence. Complications of pregnancy remain common. The maternal mortality is as high as $1 / 14$ births. Women commonly have five to six births. In many countries there is only 1 physician per 20,000 people, whereas in the USA there are 40 . The Csection rate is $5.8 \%$, whereas in high income countries it averages $29.6 \%$. Anesthesia is available to only $25 \%$ of those women. Less than half of low income women are attended by a professional during childbirth [1].

In Ethiopia, 18,000 women have obstructed labor each year. Half die and the remainder lose a baby and gain a fistula. A fistula meant sure death for a woman as she lost all support and was ostracized. Many committed suicide. Profoundly affected by this situation, in 1974, Drs. Reginald and Catherine Hamlin from Australia began a fistula hospital in Ethiopia (www.hamlinfistula.org). This hospital remains an important institution. In addition to repairing these fistulae, they train surgeons, have a midwifery school, and have a village where the recovering women can live and learn a trade. Too early a return to their home often meant return to sexual activity and too soon a pregnancy which would undo the repair.

Since then many fistula hospitals have arisen in Africa. Perhaps the most unique story is that on the Danja Fistula Hospital in Niger. Nicholas D. Kristof wrote an article in the New York Times about the plight of the women in Niger with fistulae [3]. He wrote of the dream of Dr. Steve Arrowsmith, a Michigan urologist, and Dr. Lewis Wall, an obstetrician, at the Washington University in St. Louis who wanted to build a fistula hospital in Niger. New York Times subscribers contributed US\$500,000 to make this a reality. The hospital provides comprehensive care and builds capacity by training health care providers.

Despite the United Nations outlawing female circumcision the practice remains common. This further increases the problems of childbirth. In some countries the practice is so much part of the culture that many women support it. Now that it is illegal, girls are circumcised at a younger age where they can be hidden more easily. The practice is not spoken about.
In the last decade there has been increased focus on the plight of the low income countries by academic institutions and charitable organizations. Several have developed global initiatives for education, research, and care. It is clear that these initiatives must be mutually beneficial, must be sustainable, and must provide solutions to local problems. Exchange programs are very useful. Because some of the earlier programs have not been sensitive to local issues and have left people without follow-up care, guidelines are being established for these programs. One such program published by the International Development Committee of the Association of Surgeons of Great Britain and Ireland has been endorsed by the major African surgical organizations and others. These emphasize capacity building, sustainability, and comprehensive care [4].

Interest of students and residents for experiences in and support of initiatives in low income countries is high. A survey of the residents in the Resident and Associate Society (RAS) of the ACS which had a response rate of $11 \%$ showed that $51 \%$ had worked internationally and $92 \%$ were interested in doing so; $73 \%$ stated even if it meant giving up vacation [5].

The ACS has had a program Operation Giving Back which organizes humanitarian aid and disaster relief throughout the world. They have a simulation center in Ghana. This past year they hosted a meeting of International Presidents of the Colleges of Surgeons to look at how we could interact to improve quality and accessibility of surgical care through education, skills training, and advocacy (www.facs.org).

Another rather recent development was the formation of the Alliance for Surgery and Anesthesia Presence (ASAP) by Dr. Kelly McQueen, an anesthesiologist. The group has broad representation of anesthesiologists, surgeons, and obstetricians worldwide. They meet annually to exchange information, present research, share best practices, and network. They focus primarily on low income countries (www.asaptoday.org).

Now that we recognize these issues of disparity we can more easily act. Morally we are obligated to do so. The American Urogynecologic Society has recently formed an International Relations Committee which can play an active role in improving the situation for women in low income countries. The members have skills that are desperately needed. They must develop a strategic plan to maximize benefit.

All of us can encourage our medical schools and residencies to have global health programs. We must support the WHA resolution to the WHO to include surgical care in its global health mission. Their 2000 Millennium program has reduced infant and maternal mortality. We must build on that initiative. We should support charitable programs that build sustainable, capacity building programs. We can all support charities that provide economic development for women.

As a tribute to the work begun by Dr. J. Marion Sims well over a century ago, we must continue to work to improve the health and well-being of all women. 


\section{Conflicts of interest None.}

\section{References}

1. Casey KM (2012) Putting the "global" back in global health. Arch Surg 147:404-407

2. www.WHO.int. Millennium Development Goals
3. Kristof N (2013) New York Times. July 13

4. Grimes CE, Maraka J, Kingsnorth AN et al (2013) Guidelines for surgeons on establishing projects in low-income countries. World J Surg 37:1203-1207

5. Powell AC, Casey K, Liewehr DJ, Hayanga A, James TA, Cherr GS (2009) Results of a national survey of surgical resident interest in international experiences, electives, and volunteerism. J Am Coll Surg 208(2):304-312 